\title{
Daily Testosterone and Gonadotropin Levels Are Similar in Azoospermic and Nonazoospermic Normal Men Administered Weekly Testosterone: Implications for Male Contraceptive Development
}

\author{
JOHN K. AMORY, BRADLEY D. ANAWALT, WILLIAM J. BREMNER, AND ALVIN M. MATSUMOTO \\ From the Population Center for Research in Reproduction, Geriatric Research Education and Clinical Center, \\ Veterans Affairs Puget Sound Health Care System; and Department of Medicine, University of Washington School of \\ Medicine, Seattle, Washington.
}

\begin{abstract}
Weekly intramuscular administration of testosterone esters such as testosterone enanthate (TE) suppresses gonadotropins and spermatogenesis and has been studied as a male contraceptive. For unknown reasons, however, some men fail to achieve azoospermia with such regimens. We hypothesized that either 1) daily circulating serum fluoroimmunoreactive gonadotropins were higher or testosterone levels were lower during the weekly injection interval, or 2) monthly circulating bioactive gonadotropin levels were higher in nonazoospermic men. We therefore analyzed daily testosterone and fluoroimmunoreactive gonadotropin levels as well as pooled monthly bioactive and fluoroimmunoreactive gonadotropin levels in normal men receiving chronic TE injections and correlated these levels with sperm production. After a 3-month control period, 51 normal men were randomly assigned to receive intramuscular TE at $25 \mathrm{mg}(\mathrm{n}=10), 50 \mathrm{mg}(\mathrm{n}=9), 100 \mathrm{mg}(\mathrm{n}=10), 300 \mathrm{mg}(\mathrm{n}=$ $10)$, or placebo $(n=12)$ weekly for 6 months. After 5 months of testosterone administration, morning testosterone and fluoroimmunoreactive follicle-stimulating hormone $(\mathrm{FSH})$ and luteinizing hormone $(\mathrm{LH})$ levels were measured daily for a 1-week period between TE injections. In addition, fluoroimmunoreactive and bioactive FSH and $\mathrm{LH}$ levels were measured in pooled monthly blood samples
\end{abstract}

drawn just before the next TE injection. In the 100-mg and 300-mg TE groups, mean monthly fluoroimmunoreactive FSH and LH levels were suppressed by $86 \%-97 \%$, bioactive $\mathrm{FSH}$ and $\mathrm{LH}$ levels by $62 \%-80 \%$, and roughly half the subjects became azoospermic. In the 1-week period of month 6 , daily testosterone levels between TE injections were within the normal range in men receiving placebo, or 25 or $50 \mathrm{mg}$ of weekly TE, but were significantly elevated in men receiving 100 or $300 \mathrm{mg}$ of weekly TE. At no point during treatment, however, were there significant differences in daily testosterone or fluoroimmunoreactive gonadotropin levels, or monthly bioactive gonadotropin levels between men achieving azoospermia and those with persistent spermatogenesis. This study, therefore, demonstrates that neither monthly nor daily differences in serum testosterone, or fluoroimmunoreactive or bioactive gonadotropins explain why some men fail to completely suppress their sperm counts to zero with weekly TE administration. Innate differences in the testicle's ability to maintain spermatogenesis in a low-gonadotropin environment may explain persistent spermatogenesis in some men treated with androgen-based contraceptive regimens.

Key words: Contraception, gonadotropins, azoospermia.

J Androl 2001;22:1053-1060
$\mathrm{T}$ he development of a reversible male contraceptive would significantly broaden the contraceptive choices for couples who wish to limit their family size. Exogenous testosterone administration has shown promise as a potential hormonal contraceptive for men, especially for those who achieve azoospermia (World Health Organization [WHO], 1990), but only $50 \%-75 \%$ of white men

This work was supported by Environmental Protection Agency grant DW-36931233-01-1, National Institutes of Health grant P-50-HD-12629, and Department of Veterans Affairs research funds. Portions of this study were conducted in the Clinical Research Center at the University of Washington, which is supported by National Institutes of Health grant RR-37.

Correspondence to: Dr John K. Amory, Box 356429, University of Washington, 1959 NE Pacific Street, Seattle, WA 98195 (e-mail: jamory@ u.washington.edu).

Received for publication March 12, 2001; accepted for publication May 30, 2001. achieve azoospermia with this approach (Handelsman et al, 1995; WHO, 1996; Amory and Bremner, 1998).

Exogenous testosterone suppresses spermatogenesis primarily through feedback inhibition of the secretion of the pituitary gonadotropins, follicle-stimulating hormone (FSH) and luteinizing hormone (LH), which are required for spermatogenesis and testosterone synthesis. We have previously reported that weekly testosterone enanthate (TE) administration in 100- or 300-mg doses induced azoospermia in only about half of normal young men (Matsumoto, 1990). Why sperm counts in some men suppress to zero whereas other subjects continue to produce sperm when administered weekly TE is unclear. Monthly preinjection testosterone and gonadotropin levels in men given weekly intramuscular TE have been shown not to correlate with sperm counts (Wallace et al, 1993); however, more comprehensive assessment of hormone levels has 
not been undertaken. We hypothesized that men who fail to suppress their sperm counts to zero may have either 1) lower daily testosterone levels or higher fluoroimmunoreactive gonadotropin levels at some point between weekly TE injections; or 2) less suppression of monthly bioactive fluoroimmunoreactive gonadotropins, which allows low levels of spermatogenesis to persist. To our knowledge, monthly bioactive gonadotropin concentrations, and daily testosterone and gonadotropin levels using highly sensitive fluoroimmunoreactive gonadotropin assays in men injected chronically with varying doses of weekly TE, have not previously been reported. Therefore, we measured monthly serum fluoroimmunoreactive and bioactive $\mathrm{FSH}$ and $\mathrm{LH}$, and daily serum fluoroimmunoreactive testosterone, FSH, and LH levels over a 1-week period between TE injections in normal eugonadal young men who had received weekly doses of 25, 50, 100, 300 mg TE or placebo testosterone for 5 months. To test our hypothesis, we compared the hormone levels between TE injections in those men who suppressed to azoospermia and those who did not.

\section{Materials and Methods}

\section{Subjects}

Fifty-one normal men (mean age, $29 \pm 1$ year) were studied. All had a normal medical history; physical examination; hematologic and blood chemistry studies; serum cholesterol and triglyceride levels; urinalysis; and basal serum testosterone, FSH, and LH levels. Six seminal fluid analyses, obtained at 2-week intervals over 3 months, were normal in all of these subjects (ie, sperm concentration greater than 20 million/mL; motility greater than 50\%; greater than $60 \%$ oval forms [WHO guidelines]). Information on these subjects (specifically, monthly testosterone and gonadotropin levels using an older, less-sensitive radioimmunoassay and sperm counts) has been previously reported in a study investigating the dose-response effects of TE administration (Matsumoto et al, 1990). There were no differences in baseline hormone levels or testis size between treatment groups. Forty-four of 51 subjects completed the study; the other 7 subjects (3 in the placebo group, 1 in the $25 \mathrm{mg}$ group, 2 in the $50 \mathrm{mg}$ group, and 1 in the $300 \mathrm{mg}$ group) were disqualified from the study and not included in the analysis because they failed to report for all scheduled blood draws.

\section{Experimental Design}

The first 3 months of the study constituted a control period during which observations and measurements were performed in each subject, but no hormones were administered. After the control period, subjects were randomly assigned in a balanced, double-blind design into 1 of 5 treatment groups: sesame oil vehicle (placebo) $1 \mathrm{~mL}$, intramuscular weekly $(\mathrm{n}=12)$; or TE in sesame oil vehicle (Delatestryl, Squibb and Sons, Princeton, NJ) $25 \mathrm{mg}$ $(\mathrm{n}=10), 50 \mathrm{mg}(\mathrm{n}=9), 100 \mathrm{mg}(\mathrm{n}=10)$, or $300 \mathrm{mg}(\mathrm{n}=$ 10) each in $1 \mathrm{~mL}$, intramuscularly, weekly for 6 months.
All injections were administered by an investigator or a registered nurse. Subjects were dropped from the study if they missed 2 consecutive injections or more than a total of 2 injections during the treatment period. The University of Washington Human Subjects Review Committee and the Veterans Affairs Puget Sound Health Care System Research and Development Committee approved the study protocol.

\section{Measurements}

Serum FSH and LH levels by fluoroimmunoreactive assay were measured in all monthly samples, and FSH and LH bioactivity was measured using in vitro bioassays in pooled samples composed of equal aliquots of monthly samples from the control and treatment periods. After 5 months of TE treatment, subjects underwent 1 week of daily morning blood draws for measurement of serum testosterone by radioimmunoassay, and FSH and LH by fluoroimmunometric assay just before a TE injection. Samples were collected in 1988-89 and immediately frozen. Samples were thawed once in 1989 for measurement of testosterone. Samples were then stored at $-70^{\circ} \mathrm{C}$ until 1995 when they were reanalyzed with the newer, more-sensitive, fluoroimmunoreactive and bioactive gonadotropin assays. Throughout the study, all subjects submitted twice monthly seminal fluid specimens, obtained by masturbation, after 48 hours of abstinence from ejaculation.

\section{Hormone Assays}

Serum testosterone levels were measured by radioimmunoassay using reagents from the WHO-matched reagent program by methods previously described (Matsumoto et al, 1983). The assay sensitivity was $0.5 \mathrm{ng} / \mathrm{mL}$; the intraassay and interassay coefficients of variation (CVs) were $5.1 \%$ and $9.8 \%$, respectively. Serum FSH and LH were measured in the Delfia fluoroimmunometric assay (Wallac Oy, Turku, Finland). The sensitivity of the Delfia fluoroimmunometric assay for FSH was $0.016 \mathrm{IU} / \mathrm{L}$ with an intraassay CV $2.5 \%$ and an interassay CV of $4.0 \%$ at 2 IU/L, and intraassay and interassay CVs of $5.1 \%$ and $8.3 \%$, respectively, at 0.05 IU/L. The sensitivity of the Delfia fluoroimmunometric assay for $\mathrm{LH}$ was $0.018 \mathrm{IU} / \mathrm{L}$, with an intraassay $\mathrm{CV}$ of $2.8 \%$, an interassay $\mathrm{CV}$ of $5.0 \%$ at $2 \mathrm{IU} / \mathrm{L}$, and intraassay and interassay CVs of $6.2 \%$ and $9.4 \%$, respectively, at $0.05 \mathrm{IU} /$ L. Serum bioactive FSH and LH levels were determined by in vitro rat granulosa cell and in vitro mouse Leydig cell bioassays, respectively, as previously described (Tenover et al, 1987; Dahl et al, 1989). The sensitivity of both the FSH and LH bioassays was $15 \mu \mathrm{g} / \mathrm{L}$. The intraassay and interassay variabilities of the FSH bioassay were $10 \%$ and $14 \%$, respectively, at $200 \mu \mathrm{g} / \mathrm{L}$; and $15 \%$ and $18 \%$, respectively, at $50 \mu \mathrm{g} / \mathrm{L}$. The intraassay and interassay variabilities of the LH bioassay were $10 \%$ and $16 \%$, respectively, at $200 \mu \mathrm{g} / \mathrm{L}$; and $13 \%$ and $19 \%$, respectively, at 50 $\mu \mathrm{g} / \mathrm{L}$. All samples from an individual were run in the same assay and each assay contained subjects from all experimental groups. There appears to be a negligible effect of long-term storage on samples as both gonadotropin assays have been shown to be highly reproducible for periods exceeding 5 years on samples frozen at $-70^{\circ} \mathrm{C}$. 


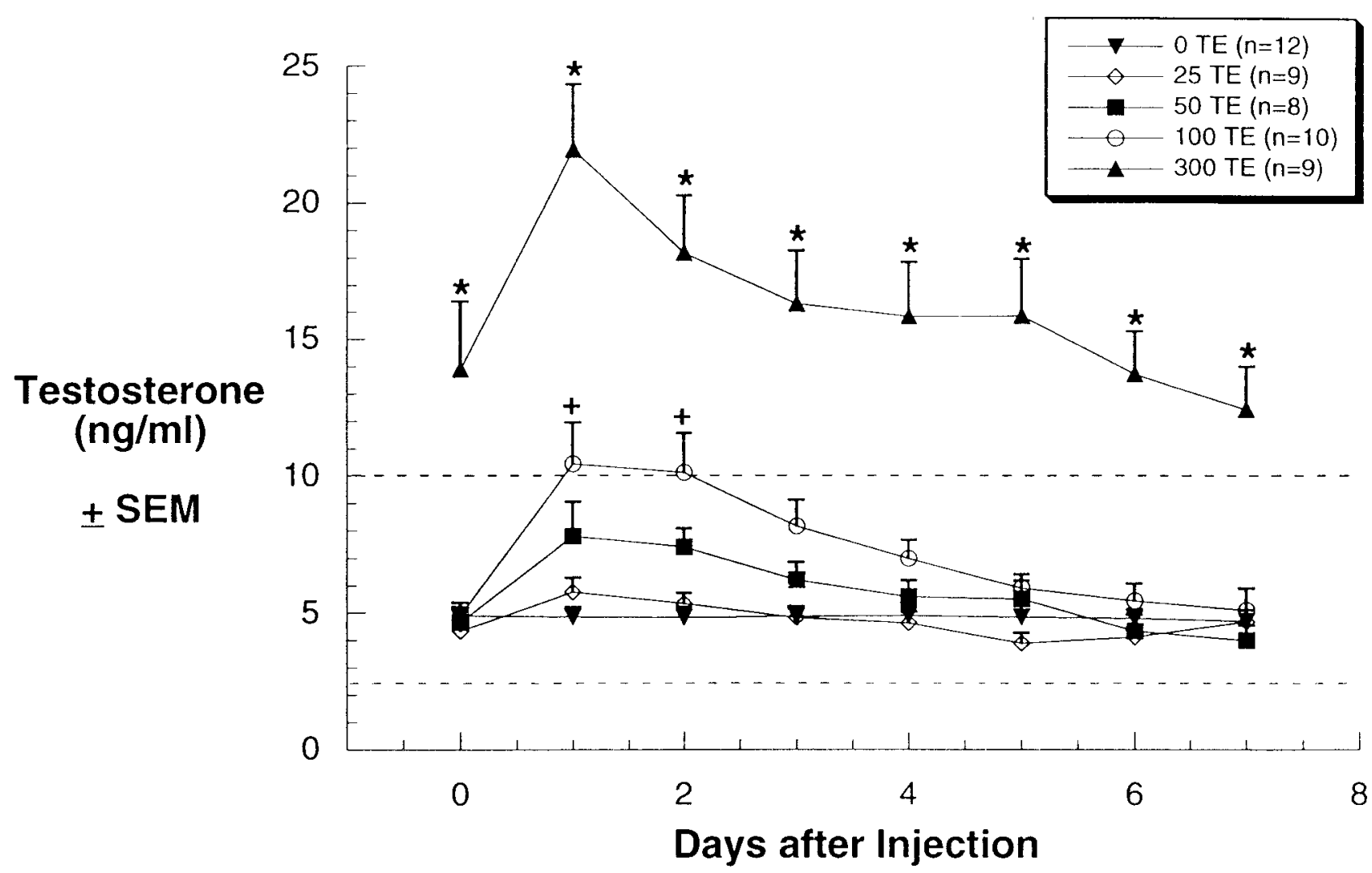

Figure 1. Daily serum testosterone levels $(\mathrm{ng} / \mathrm{mL})$ are higher in normal men after receiving 300 mg of intramuscular TE weekly in treatment month 6 (mean \pm SEM). * indicates significant at $P<.05$ from placebo, $25 \mathrm{mg}, 50 \mathrm{mg}$, and $100 \mathrm{mg}$ groups; + , significant at $P<.05$ from placebo.

\section{Sperm Counts}

Azoospermia was defined as 2 or more consecutive sperm counts of zero. Sperm counts were determined with a Coulter counter (Coulter Electronics, Inc, Hialeah, Fla), and concentrations less than 15 million/mL were confirmed by direct determination using a hemocytometer (Bremner et al, 1981).

\section{Statistical Analysis}

Mean daily testosterone, LH, and FSH levels ( \pm SEM) were calculated for each group. When levels were below the limit of detectability of the fluoroimmunometric assay for gonadotropins (namely, $0.016 \mathrm{IU} / \mathrm{L}$ for FSH and $0.018 \mathrm{IU} / \mathrm{L}$ for $\mathrm{LH}$ ), these lowest detectable values were used in the analysis. Comparisons between hormone levels among the 5 groups were determined by ANOVA with the Duncan post hoc correction. No subjects in the 25-mg or 50-mg TE or placebo group achieved azoospermia. Therefore, a $t$-test was used for comparisons between subjects achieving azoospermia and those with persistent spermatogenesis in the 100- and 300-mg TE groups. For all comparisons, $P<.05$ was considered significant.

\section{Results}

\section{Daily Testosterone and Gonadotropin Levels Between TE Injections}

Men receiving placebo, or $25 \mathrm{mg}$ or $50 \mathrm{mg}$ of TE weekly had testosterone levels within the normal range $(2.8-10$ $\mathrm{ng} / \mathrm{mL}$ ) throughout the week of daily blood draws during treatment month 6 (Figure 1). At no point during the weekly injection interval were the serum testosterone levels significantly different among these 3 groups, although there was a discernable pattern of small increases, then decreases through the week in the men receiving TE (Figure 1). Men receiving $100 \mathrm{mg}$ TE weekly had values of serum testosterone at or slightly above the normal range, and significantly different from placebo levels, for the first 2 days after the injection, but serum testosterone was within the normal range from days 3 through 7 after the injection. Men receiving $300 \mathrm{mg}$ TE weekly had serum testosterone levels above the normal range throughout the injection interval (mean serum testosterone, $14.6 \pm 1.6$ $\mathrm{ng} / \mathrm{mL}$ ). These testosterone levels were significantly elevated compared with all other groups at every time point $(P<.001$ compared with placebo; $P<.05$ compared with $100 \mathrm{mg}$ weekly TE).

Daily serum fluoroimmunoreactive FSH and LH levels were decreased in a dose-dependent fashion after 5 months of intramuscular TE when compared with placebo (Figure 2A and B). FSH and LH levels were significantly lower compared with those of placebo throughout the injection interval in the $50 \mathrm{mg}$ TE group, but not in the 25 $\mathrm{mg}$ group. Fluoroimmunoreactive gonadotropin suppres- 

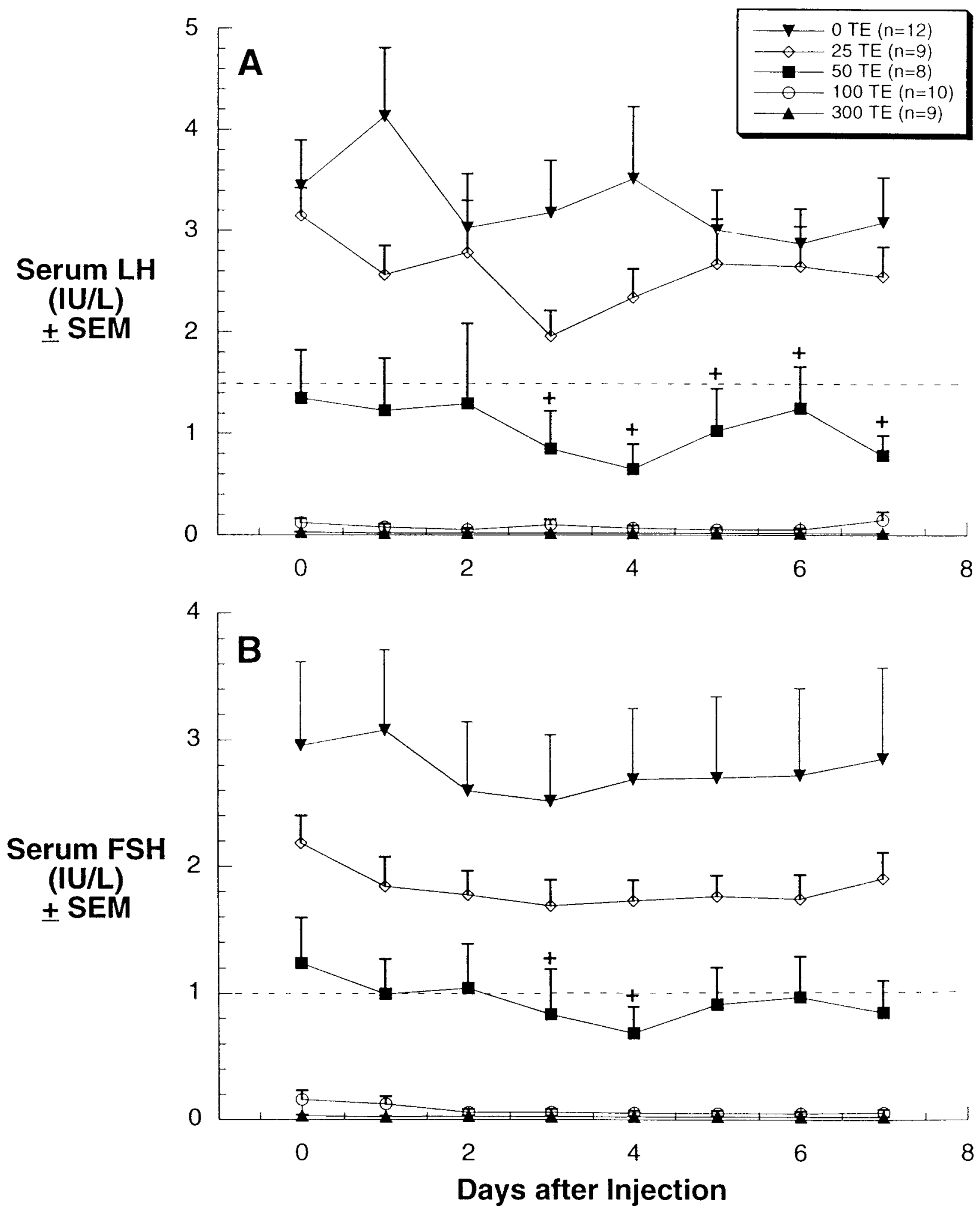

Figure 2. (A) Daily fluoroimmunoreactive serum LH (IU/L) and (B) FSH (IU/L) levels are significantly lower in normal men receiving $100 \mathrm{mg}$ and 300 $\mathrm{mg}$ of intramuscular TE weekly in treatment month 6 (means \pm SEM), $P<.05$ compared to placebo, $25 \mathrm{mg}$ TE, and $50 \mathrm{mg}$ TE at all time points. + indicates $P<.05$ compared with placebo. 
Table 1. Mean monthly fluoroimmunoreactive gonadotropins are more suppressed than bioactive gonadotropins by chronic testosterone administration to normal men*

\begin{tabular}{cllccccc}
\hline & & $\begin{array}{c}\text { Placebo } \\
(\mathrm{n}=12)\end{array}$ & $\begin{array}{c}25 \mathrm{mg} \text { TE } \\
(\mathrm{n}=9)\end{array}$ & $\begin{array}{c}50 \mathrm{mg} \text { TE } \\
(\mathrm{n}=8)\end{array}$ & $\begin{array}{c}100 \mathrm{mg} \text { TE } \\
(\mathrm{n}=10)\end{array}$ & $\begin{array}{c}300 \mathrm{mg} \text { TE } \\
(\mathrm{n}=9)\end{array}$ \\
\hline LH & FIR $(\mathrm{IU} / \mathrm{L}) \dagger$ & Control & $\ldots$ & $\ldots$ & $\ldots$ & $3.5 \pm 0.3$ & $3.8 \pm 0.7$ \\
& & Treatment & $\ldots$ & $\ldots$ & $\ldots$ & $0.4 \pm 0.06(88)$ & $0.06 \pm 0.01 \pm(97)$ \\
& $\mathrm{BA}(\mu \mathrm{g} / \mathrm{L}) \dagger$ & Control & $266 \pm 41$ & $230 \pm 29$ & $149 \pm 24$ & $241 \pm 39$ & $242 \pm 52$ \\
& & Treatment & $244 \pm 36(8)$ & $161 \pm 25(30)$ & $74 \pm 18(50)$ & $43 \pm 6(82)$ & $51 \pm 9(79)$ \\
FSH & FIR $(\mathrm{IU} / \mathrm{L})$ & Control & $\ldots$ & $\ldots$ & $\ldots$ & $2.1 \pm 0.4$ & $2.4 \pm 0.4$ \\
& & Treatment & $\ldots$ & $\ldots$ & $\ldots$ & $0.3 \pm 0.07(86)$ & $0.07 \pm 0.01 \pm(97)$ \\
& $\mathrm{BA}(\mu \mathrm{g} / \mathrm{L})$ & Control & $273 \pm 31$ & $269 \pm 20$ & $333 \pm 35$ & $340 \pm 37$ & $336 \pm 34$ \\
& & Treatment & $287 \pm 32(-5)$ & $212 \pm 28(21)$ & $168 \pm 27(50)$ & $109 \pm 15(68)$ & $129 \pm 14(62)$ \\
\hline
\end{tabular}

* Values are expressed as mean \pm SEM (\% suppression compared with control).

† FIR indicates fluoroimmunoreactive gonadotropins; BA, bioactive gonadotropins.

$\ddagger P<.05$ compared with $100 \mathrm{mg}$ TE.

sion was close to complete (greater than 97\%) in the 100 $\mathrm{mg}$ and $300 \mathrm{mg}$ TE groups throughout the week-long period after TE injection (mean FSH, $0.06 \pm 0.02 \mathrm{IU} / \mathrm{L}$ and $0.02 \pm 0.01 \mathrm{IU} / \mathrm{L} ;$ mean $\mathrm{LH}, 0.07 \pm 0.02 \mathrm{IU} / \mathrm{L}$ and 0.02 $\pm 0.01 \mathrm{IU} / \mathrm{L} ; P<.001$ vs placebo; $P<.05 \mathrm{vs} 25 \mathrm{mg}$ and $50 \mathrm{mg} \mathrm{TE})$. There were no statistically significant differences in daily gonadotropin levels between the men in the $100 \mathrm{mg}$ and $300 \mathrm{mg}$ TE groups during the 1-week period. No subjects in the placebo, $25 \mathrm{mg}$, or $50 \mathrm{mg}$ TE groups had gonadotropins suppressed below the lower limit of the assay. Seven of 10 and 8 of 9 men in the 100 $\mathrm{mg}$ and $300 \mathrm{mg}$ TE groups, respectively, had either an FSH or an LH level below this level $(P=\mathrm{NS})$.

\section{Monthly Bioactive and Fluoroimmunoreactive Gonadotropins}

Both monthly bioactive and fluoroimmunoreactive gonadotropins were suppressed in a dose-dependent fashion by exogenous weekly TE when compared with baseline (Table 1). In the $100 \mathrm{mg}$ and $300 \mathrm{mg}$ TE groups, the pooled monthly fluoroimmunoreactive gonadotropins were more significantly suppressed by $300 \mathrm{mg}$ than by $100 \mathrm{mg}$ TE, but serum bioactive gonadotropin levels were not significantly different between men receiving $300 \mathrm{mg}$ of TE and $100 \mathrm{mg}$ of TE. Fluoroimmunoreactive gonadotropins were more suppressed than the bioactive gonadotropins in both the $100 \mathrm{mg}$ and $300 \mathrm{mg}$ TE groups. Monthly fluoroimmunoreactive FSH was suppressed by $86 \%$ and $97 \%$ in the $100 \mathrm{mg}$ and $300 \mathrm{mg}$ TE groups, respectively, whereas fluoroimmunoreactive LH was suppressed by $88 \%$ and $97 \%$, respectively, in the same groups. Monthly bioactive LH was suppressed by $82 \%$ and $79 \%$, respectively, in the $100 \mathrm{mg}$ and $300 \mathrm{mg}$ TE groups, whereas bioactive FSH was depressed only by $68 \%$ and $62 \%$, respectively, in these same groups.

\section{Sperm Counts}

Sperm counts in the placebo and $25 \mathrm{mg}$ TE groups did not differ significantly from baseline levels. Sperm counts in the $50 \mathrm{mg}$ TE groups were suppressed by $60 \%$ from baseline levels (Matsumoto, 1990), and no subject in the placebo, $25 \mathrm{mg} \mathrm{TE}$, or $50 \mathrm{mg}$ TE group achieved azoospermia during the 6-month study period. Five of 10 men (50\%) in the $100 \mathrm{mg}$ group achieved azoospermia, and 5 of 9 men $(55 \%)$ in the $300 \mathrm{mg}$ group achieved azoospermia $(P=$ NS). Among the oligoazoospermic men, the average nadir sperm count in the $100 \mathrm{mg}$ TE group was $1.9 \pm 2.7$ million $/ \mathrm{mL}$ compared with $11.4 \pm 10.7$ million/ $\mathrm{mL}$ in the $300 \mathrm{mg}$ TE group ( $P=\mathrm{NS})$.

\section{Comparison of Azoospermic and Nonazoospermic Subjects}

Because only subjects in the 2 high-dose testosterone groups achieved azoospermia, these 2 groups were compared for differences in hormone levels between the subjects who achieved azoospermia and those who did not. There were significant differences in pretreatment fluoroimmunoreactive gonadotropin levels between those who suppressed to azoospermia and those who did not (fluoroimmunoreactive FSH, $2.82 \pm 0.36$ IU/L in azoospermia, and $1.58 \pm 0.21 \mathrm{IU} / \mathrm{L}$ in oligoazoospermia; fluoroimmunoreactive $\mathrm{LH}, 4.36 \pm 0.58 \mathrm{IU} / \mathrm{L}$ in azoospermia, and $2.83 \pm 0.34 \mathrm{IU} / \mathrm{L}$ in oligoazoospermia; $P<.05$ for both comparisons) and sperm counts $(65 \pm 12$ million/ $\mathrm{mL}$ for azoospermia vs $121 \pm 18 \mathrm{million} / \mathrm{mL}$ for oligoazoospermia: $P<.05)$. However, there were no significant differences in baseline serum testosterone, bioactivity, or testis size between those who suppressed to azoospermia and those who did not. Moreover, there were no differences in serum testosterone at any point in the injection interval in men in the $100 \mathrm{mg}$ and $300 \mathrm{mg}$ groups who achieved azoospermia compared with those who persistently had sperm in their ejaculates (Table 2). In addition, there were no differences in serum fluoroimmunoreactive gonadotropins during the 1-week interval after TE injection between azoospermic and nonazoospermic men. There were also no differences in monthly bioreactive 
Table 2. Daily serum testosterone, LH and FSH (mean \pm SEM) were not different between azoospermic (Azo: $n=10)$ and oligoazoospermic (Oligo; $n=9$ ) men during chronic testosterone administration of $100 \mathrm{mg}$ or $300 \mathrm{mg}$ TE weekly. $P=N S$ for all comparisons

\begin{tabular}{lccrrrrrr}
\hline & Day 0 & Day 1 & \multicolumn{1}{c}{ Day 2 } & \multicolumn{1}{c}{ Day 3 } & \multicolumn{1}{c}{ Day 4 } & \multicolumn{1}{c}{ Day 5 } & Day 6 & Day 7 \\
\hline T-Azo $(\mathrm{ng} / \mathrm{mL})$ & $9.39 \pm 2.45$ & $14.7 \pm 2.56$ & $12.1 \pm 2.12$ & $11.9 \pm 2.08$ & $11.3 \pm 2.29$ & $10.9 \pm 2.23$ & $9.57 \pm 1.82$ & $8.71 \pm 1.62$ \\
T-Oligo $(\mathrm{ng} / \mathrm{mL})$ & $8.93 \pm 2.02$ & $17.2 \pm 2.90$ & $15.36 \pm 2.28$ & $12.21 \pm 1.98$ & $11.09 \pm 1.74$ & $10.94 \pm 2.43$ & $9.17 \pm 1.79$ & $8.41 \pm 1.87$ \\
LH-Azo (IU/L) & $0.06 \pm 0.02$ & $0.05 \pm 0.03$ & $0.04 \pm 0.01$ & $0.04 \pm 0.02$ & $0.03 \pm 0.01$ & $0.03 \pm 0.01$ & $0.03 \pm 0.01$ & $0.10 \pm 0.07$ \\
LH-Oligo (IU/L) & $0.10 \pm 0.04$ & $0.06 \pm 0.02$ & $0.04 \pm 0.01$ & $0.08 \pm 0.05$ & $0.07 \pm 0.03$ & $0.05 \pm 0.02$ & $0.04 \pm 0.01$ & $0.07 \pm 0.03$ \\
FSH-Azo (IU/L) & $0.14 \pm 0.07$ & $0.12 \pm 0.06$ & $0.06 \pm 0.03$ & $0.06 \pm 0.03$ & $0.05 \pm 0.02$ & $0.05 \pm 0.02$ & $0.05 \pm 0.02$ & $0.05 \pm 0.03$ \\
FSH-Oligo (IU/L) & $0.05 \pm 0.02$ & $0.03 \pm 0.01$ & $0.03 \pm 0.01$ & $0.03 \pm 0.00$ & $0.03 \pm 0.00$ & $0.03 \pm 0.00$ & $0.02 \pm 0.00$ & $0.03 \pm 0.00$ \\
\hline
\end{tabular}

gonadotropin levels during treatment between those who achieved azoospermia and those who did not (mean bioactive FSH, $134 \pm 15 \mu \mathrm{g} / \mathrm{L}$ and $103 \pm 12 \mu \mathrm{g} / \mathrm{L}$; mean bioactive $\mathrm{LH}, 41 \pm 6 \mu \mathrm{g} / \mathrm{L}$ and $54 \pm 9 \mu \mathrm{g} / \mathrm{L}$; for azoospermic and nonazoospermic subjects; $P=\mathrm{NS}$ ).

\section{Discussion}

In summary, we have shown that in normal men receiving chronic TE injections, daily serum testosterone levels are significantly elevated in subjects receiving $100 \mathrm{mg}$ or 300 mg of weekly TE. These supranormal levels of testosterone are sufficient to suppress both pooled monthly and daily serum fluoroimmunoreactive gonadotropins by $85 \%-97 \%$, and monthly bioactive FSH by $65 \%$ and bioactive LH by $80 \%$ during treatment compared with baseline.

Roughly half of the subjects in the $100 \mathrm{mg}$ and 300 mg TE groups achieved azoospermia, but there were no differences in daily serum testosterone or daily fluoroimmunoreactive gonadotropin levels or monthly fluoroimmunoreactive or bioactive gonadotropin concentrations in those achieving azoospermia and those who did not. These findings demonstrate that the failure to induce azoospermia with weekly TE injections in normal men is not a function of measurable daily differences in serum testosterone, serum fluoroimmunoreactive gonadotropin levels, or monthly bioactive gonadotropin levels during treatment. This conclusion extends the findings that monthly differences in testosterone and immunoreactive gonadotropins are unlikely to be responsible for the maintenance of minor degrees of spermatogenesis on contraceptivedosage testosterone (Wallace et al, 1993; Handelsman et al, 1995), and demonstrates that simply increasing the dose of testosterone in male contraceptives is unlikely to result in greater efficacy.

It is clear from our study that increased negative feedback from the higher levels of circulating androgens in the $300 \mathrm{mg}$ TE group was able to significantly decrease fluoroimmunoreactive gonadotropins compared with the $100 \mathrm{mg}$ TE group, but was unable to further decrease gonadotropin bioactivity. This implies that significant gonadotropin activity may persist in vivo despite almost complete suppression of serum fluoroimmunoreactive gonadotropins. This activity is likely due either to relatively high residual bioactivity from the low levels of fluoroimmunoreactive gonadotropins or bioactivity from other sources. Because sera from men with idiopathic hypogonadotropic hypogonadism demonstrates bioactivity levels at or below the limit of sensitivity of this assay (data not shown), we believe that the bioactivity measured in the present study is accurate and may be enough to sustain spermatogenesis in some men. However, the absolute level of bioactivity required to maintain spermatogenesis clearly differs between individuals. This finding suggests that measurement of serum bioactive gonadotropins, and bioactive FSH in particular, may be a more useful and sensitive indicator of gonadotropin activity in hormonebased male contraceptive trials than fluoroimmunoreactive gonadotropin values, which are likely to be at or near the limit of detectability. In addition, future efforts at improving contraceptive efficacy could be directed specifically at reducing gonadotropin bioactivity.

Although there was a difference in baseline fluoroimmunoreactive gonadotropins between azoospermic and oligoazoospermic men in the $100 \mathrm{mg}$ TE and $300 \mathrm{mg}$ TE groups, this is an unlikely explanation for the difference between men who suppressed to azoospermia and those who did not for several reasons. First, these baseline values were within the normal range. Second, the baseline bioactive gonadotropin levels were not different. Last, baseline differences in fluoroimmunoreactive gonadotropins have not been demonstrated in previous studies of this issue (Wallace et al, 1993).

A potential drawback to this study is the fact that the samples were 6 to 7 years old when reanalyzed using the newer, more-sensitive fluoroimmunoassay and the bioassay. However, we do not believe that the results obtained were adversely affected for two reasons: first, the samples had not been thawed more than once prior to the assays used in the present study; and second, all samples from a given subject were run in the same assay, thereby limiting the potential for variability. In addition, our expe- 
rience with the both the Delfia and bioactive gonadotropin assays has demonstrated that samples such as those used in this study are remarkably stable over long periods of time when kept properly frozen.

It is clear from recent contraceptive trials that further suppression of serum immunoreactive gonadotropins mediated by the addition of a progestin can improve rates of azoospermia to 70\%-90\% (Meriggiola et al, 1998; Anawalt et al, 1999; Wu et al, 1999). In these studies, the levels of circulating gonadotropins in subjects receiving TE in combination with a progestin are significantly lower than control groups receiving TE alone. Some men treated with testosterone plus a progestin, however, still fail to suppress their sperm counts to zero on these combined regimens and, as in this study, there are no apparent differences in the gonadotropin levels among men who suppress to azoospermia and those who do not. One must conclude, therefore, that while further lowering of serum gonadotropin levels improves the percentage of subjects who achieve azoospermia, it also suggests that serum gonadotropin levels within a given hormonal regimen may not distinguish between men who will achieve azoospermia and those who will not.

Explanations for differences between subjects who become azoospermic and those who do not with exogenous testosterone administration have been proposed. For example, Anderson and colleagues (1996) have suggested that this difference may be due to greater $5 \alpha$-reductase (type II) activity in the testes, resulting in higher dihydrotestosterone levels in the serum and seminal plasma of patients who failed to suppress to azoospermia on 200 mg of weekly TE. However, coadministration of testosterone and a type II $5 \alpha$-reductase inhibitor (finasteride) did not enhance suppression of spermatogenesis in 2 recent studies (McLachlan et al, 2000; Kinniburgh et al, 2001).

Alternatively, growth hormone $(\mathrm{GH})$ has recently been shown to support spermatogenesis in rats chemically hypophysectomized with gonadotropin-releasing hormone agonists (Ohyama et al, 1999). If GH acts as a "cogonadotropin," it may be possible that differences in the GH/ insulin-like growth factor-1 axis could discriminate between men who suppress to azoospermia and those who do not. Finally, molecular approaches have demonstrated the importance androgen receptor polymorphisms play in male infertility (Yong et al, 2000). Differing polymorphisms of genes encoding for the androgen receptor, coactivators, or gonadotropin receptors could allow for continued intratesticular testosterone production or activity of testosterone or gonadotropins, thereby enabling spermatogenesis to persist. Whatever the cause, further investigation is required to better understand the innate differences in the intratesticular environment that allow some men to continue to produce sperm in an extremely low gonado- tropin environment. Such information will be instrumental in efforts to develop safe, reversible, and effective hormonal contraception for men.

\section{Acknowledgments}

The authors thank Ms Elaine Rost for organizing the study; and Ms Consuelo Pete, Ms Dorothy McGuinness, Ms Liza Noonan, Ms Connie Nosbisch, and Mr Arlen Sarkissian for their technical assistance.

\section{References}

Amory JK, Bremner WJ. The use of testosterone as a male contraceptive. Balliere Clin Endocrinol. 1998;12:471-483.

Anawalt BD, Bebb RA, Bremner WJ, Matsumoto AM. A lower dosage levonorgestrel and testosterone combination effectively suppresses spermatogenesis and circulating gonadotropin levels with fewer metabolic effects than higher dosage combinations. J Androl. 1999;20: 407-414.

Anderson RA, Kelly RW, Wu FCW. Comparison between testosterone enanthate-induced azoospermia and oligozoospermia in a male contraceptive study. III. Higher $5 \alpha$-reductase activity in oligozoospermic men administered supraphysiological doses of testosterone. J Clin Endocrinol Metab. 1996;81:902-908.

Bremner WJ, Matsumoto AM, Sussman AM, Paulsen CA. Follicle-stimulating hormone and human spermatogenesis. J Clin Invest. 1981;68: 1044-1052.

Dahl KD, Jia X-C, Hsueh AJW. Granulosa cell aromatase bioassay for follicle-stimulating hormone. Methods Enzymol. 1989;168:414-423.

Handelsman DJ, Farley TM, Peregoudov A, Waites GM. Factors in nonuniform induction of azoospermia by testosterone enanthate in normal men. Fertil Steril. 1995;63:125-133.

Kinniburgh D, Anderson RA, Baird DT. Suppression of spermatogenesis with desogestrel and testosterone pellets is not enhanced by addition of finasteride. J Androl. 2001;22:88-95.

Matsumoto AM. Effects of chronic testosterone administration in normal men: safety and efficacy of high-dosage testosterone and parallel dose-dependent suppression of luteinizing hormone, follicle-stimulating hormone, and sperm production. J Clin Endocrinol Metab. 1990; 70:282-287.

Matsumoto AM, Paulsen CA, Hopper BR, Rebar RW, Bremner WJ. Human chorionic gonadotropin and testicular function: stimulation of testosterone, testosterone products, and sperm production despite high estradiol levels. J Clin Endocrinol Metab. 1983;56:720-728.

McLachlan RI, McDonald J, Rushford D, Robertson DM, Garrett C, Baker HWG. Efficacy and acceptability of testosterone implants, alone or in combination with a $5 \alpha$-reductase inhibitor, for male hormonal contraception. Contraception. 2000;62:73-78.

Meriggiola MC, Bremner WJ, Costantino A, DiCintio G, Flamigni C. Low dose of cyproterone acetate and testosterone enanthate for contraception in men. Hum Reprod. 1998;13:1225-1229.

Ohyama K, Iwatani N, Nakagomi Y, et al. Growth hormone advances spermatogenesis in premature rats treated with gonadotropin-releasing hormone agonist. Endocr J. 1999;46:555-562.

Tenover JS, Matsumoto AM, Plymate SR, Bremner WJ. The effects of aging in normal men on bioavailable testosterone and luteinizing hormone secretion: response to clomipheme citrate. J Clin Endocrinol Metab. 1987;65:1118-1126.

Wallace EM, Gow SM, WU FCW. Comparison between testosterone enanthate-induced azoospermia and oligoazoospermia in a male contraceptive study I: plasma luteinizing hormone, follicle stimulating 
hormone, testosterone, estradiol and inhibin concentrations. J Clin Endocrinol Metab. 1993;777:290-293.

World Health Organization. Contraceptive efficacy of testosterone-induced azoospermia in normal men. Lancet. 1990;336:995-999.

World Health Organization Task Force on Methods for the Regulation of Male Fertility. Contraceptive efficacy of testosterone-induced azoospermia and oligoazoospermia in normal men. Fertil Steril. 1996;65: $821-829$.
Wu FC, Balasubramanian R, Mulders TM, Coelingh-Bennink HJ. Oral progestogen combined with testosterone as a potential male contraceptive: additive effects between desogestrel and testosterone enanthate in suppression of spermatogenesis, pituitary-testicular axis, and lipid metabolism. J Clin Endocrinol Metab. 1999;84:112-122.

Yong EL, Lim LS, Wang Q, Mifsud A, Lim J, Ong YC, Sim KS. Androgen receptor polymorphisms and mutations in male infertility. $J$ Endocrinol Invest. 2000;23:573-577. 